\title{
The Impact of Hydric Swelling on the Mechanical Behavior of Egyptian Helwan Limestone
}

\author{
Nevin Aly ${ }^{1 *}$, Ayman Hamed ${ }^{2}$, Ahmed Abd El-Al ${ }^{3,4}$ \\ ${ }^{1}$ Engineering Science and Mathematics Department, Faculty of Petroleum and Mining Engineering, Suez University, 43533 Suez, \\ Egypt \\ 2 Geological Engineering and Geophysics Department, Faculty of Petroleum and Mining Engineering, Suez University, 43533 \\ Suez, Egypt \\ ${ }^{3}$ Civil Engineering Department, Faculty of Engineering, Najran University, P.O. Box 1988, Najran, Saudi Arabia \\ ${ }^{4}$ Geology Department, Faculty of Science, Al Azhar University, Assuit Branch, 71515 Assuit, Egypt \\ *Corresponding author, e-mail: nevin.aly@suezuniv.edu.eg
}

Received: 29 November 2019, Accepted: 05 April 2020, Published online: 21 April 2020

\begin{abstract}
This study was concerned at a limestone quarry located southeast of Helwan city, Egypt, in order to investigate the effect of hydric swelling on the geomechanical aspects of limestone rocks. The Volume of Egyptian limestones change due to the presence of clay minerals (swelling/shrinking). These changes in volume induced by changing environmental conditions, high temperature and fluctuation of the relative humidity, causes accelerated physical deterioration of limestone. The rainfall is infrequent, and it is usual for the area to have no precipitation for successive months. There is a remarkable variability in daily temperature between summer and winter. The hot and arid environment that controls the geological development can affect the engineering behavior of local sedimentary stones. Petrographic investigation by scanning electron microscopy (SEM) of Helwan limestone (biomicritic limestone) revealed the existence of smectite and glauconite within the stone. The clay fraction extracted from Helwan limestone is equal to $10 \%$ by weight. The analysis of oriented clay mounts by X-ray diffraction (XRD) confirmed the dominance of smectite in the clay fraction.

To study the effect of the clay content on the mechanical behavior of Helwan limestone, hydric swelling tests were performed at first by using a displacement sensor, afterwards, the effect of a sequence of wetting/ drying cycles on the stone strength was determined by the unconfined compressive strength (UCS) test. Results confirmed that the strength loss of the limestone is directly proportional to the degree of swelling of the clay, as expected. This highlights the importance of this parameter for selecting stones in new construction or for replacing purposes, and for establishing preventive measurements to minimize this damage in historic buildings.
\end{abstract}

\section{Keywords}

stone decay, clay swelling, hydric dilation, drying / wetting cycles, Helwan limestone

\section{Introduction}

15th of May city is an outskirt located to the east of Helwan, Egypt. It was established to be an extension of Greater Cairo due to the population increasing problem.

The studied area is located between longitudes 310 49' 13.5" - 31o 24' 03 " E and latitudes 29o 49' 40.5" - 29o 50' $55^{\prime \prime} \mathrm{N}$ and covers an area of about $600 \mathrm{~km} 2$ (Fig. 1(a, b)).

Commonly the present study deals with limestone rocks, which are an important part of the world's cultural heritage. Enough knowledge of building stone properties is an important key for effective and economic preservation of these stones when they are used for building or ornamental purposes. Although limestone rocks are often example of durability and perpetuity, many natural stone varieties have sensitivity to the different environmental conditions and damage and decay appear over time. The assessment of the effective conditions of stone built as heritage target is the most vital step of the preservation process in the future [1].

The deterioration of the stones used in built heritage happens as a result of different reasons, i.e. the crystallization of salts in the porous media [2,3], the effect of the swelling and shrinking of the stone clay content in association with the moisture content $[4,5]$. and the variation of the environmental conditions, among others. There are several references to the decay of limestones containing clays [6-9]. 


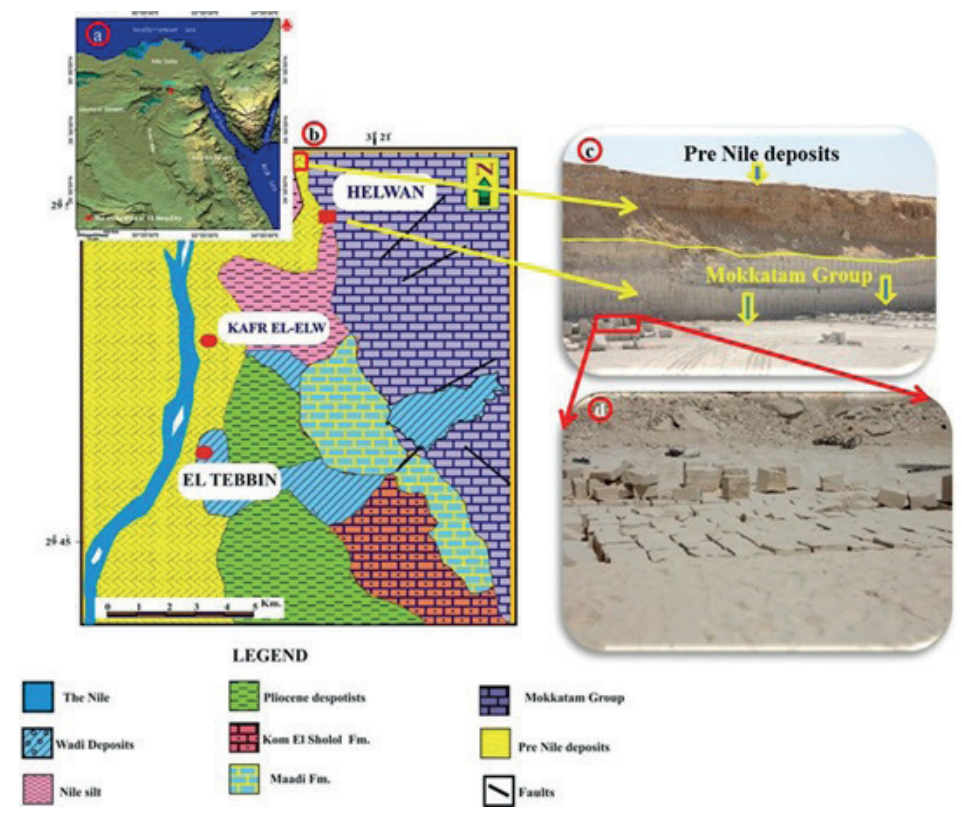

Fig. 1 (a) location map, (b) geological map of area under study, (c) site photos illustrate the Mokkatam limestone at Helwan area, (d) close view of blocks used for collected samples

Sedimentary stones are usually bearing a portion of clay minerals in their matrix. Indeed, even with the small amount, the clays made them susceptible more for weathering specially when they exposed to water content variation, and spalling or contour scaling is the most common subsequent deterioration form to be developed [10, 11]. Most of the Egyptian limestones contain clays, which can reach a proportion higher than $10 \%$ in the micrite and biomicrite limestones [12, 13]. According to Madsen and Müller-Vonmoos [14], two types of swelling can be distinguished: innercrystalline swelling, which happens due to the hydration of the exchangeable cations existing between the sheets of clay, and osmotic swelling which happens as the result of the difference between the concentration of both the ions close to the clay surface and those in the pore water of the stone. Osmotic swelling depends not only on the ion concentration but also on the type of ions, $\mathrm{pH}$ of the pore water and the type of clay [15]. Clays that swell by osmotic swelling may produce stress but is significantly limited [15].

Innercrystalline swelling induces mechanical stresses inside the stone material because of a swelling/shrinking process, which leads to the formation of microcracks and flaking of the stone surface $[16,17]$. The extent of damage depends on the type, amount and distribution of the clay [15].

During wetting and drying cycles, stone damage can take place during wetting or drying [5]. For example, when the wetted surface layer begins to dry, this results in a change in volume that is resisted by the rest of the stone still wet, generating tensile stress in between the wet and dry layers.

The swelling strain is defined as the increase of length (in $\mathrm{mm} / \mathrm{m}$ ) that the stone material expands when it gets in contact with water; The values of swelling strain above $1.5 \mathrm{~mm} / \mathrm{m}$ can be considered quite high [18].

Helwan limestone was quarried along different historic periods mainly for constructing the different built heritage at Historic Cairo and recently it used for the restoration and reconstruction of monuments at Giza and Historic Cairo [19-22]. Owing to the lack of studies on the potential, geographic distribution and petrophysical and geomechanical properties of the carbonate stones as whole, researchers should be performed new contributions to the national economy considering the limestone potential of the area. The objective of this paper is to identify and characterize the clay fraction as well as the mineralogical composition of Helwan limestone and to assess the effect of hydric swelling of this clay fraction on the engineering geological aspects of the Limestone after multiple wetting/ drying cycles. The investigations mainly have been performed on limestone of Mokkatam group in 15th may city to evaluate the effects of clay minerals which clearly considered as key factors in the swelling process.

Such information is essential for urban planners, engineers, and geologists to recommend the most appropriate type of limestones, which are suitable for construction and ornamental stones. 


\section{Geology of the site}

The area of Helwan is distinguished by gentle relief and slope from east to west. The surface of the flood plains on the banks of the River Nile made up of clay-silt layer at the top and followed below by sand and gravel layers.

Flood plain is originated through tectonic depression, and some faults perhaps bounded it. The area is divided into three geological units (Fig. 1(b)): the structural limestone plateau, which cut off by several faults, the piedmont plain and the Nile flood plain, which is created by a tectonic depression.

The sequence of rocks that formed the Greater Cairo area composed of Quaternary, Tertiary and Late Cretaceous rocks which have a thickness of about $900 \mathrm{~m}$.

Eocene outcrops are the most common rocks and mainly are composed of limestone, dolomites, and marls [23]. The Eocene Rocks consist of the following from the base to top:

- Mokattam formation is belonging to the Middle and Upper Eocene, and it is a sequence of sedimentary carbonates and less abundant clayey rocks. Mokattam formation has four units from top to base: the carbonate unit, which mainly made up of jointed sandy dolomitic limestone; the clastic unit, which is partially dolomitized marl with calcareous and ferruginous stains; the lower carbonate unit, which is sandy dolomitic limestone and marly sands interbedded together, and the lower clastic unit, which mainly made up of sandy marly limestones interbedded with shale and topped by shale (Fig. 1(b, c)).

- Maadi Formation made up of a sequence of brown and yellowish-brown to earthy-brown beds of fossiliferous and sandy limestone.

- Qasr El-Sagha Formation made up of marine to continental clastic sediments with silt and mudstone intercalations. In the lower parts Nummulites striatus and fossiliferous calcarenite are abundant.

\section{Material and methodology}

Fifty collected limestone samples were taken from an active quarry at $15^{\text {th }}$ May city ( $33 \mathrm{Km}$, South Cairo), belonging to the Mokattam geological group [24] (Fig. 1(d)). While the formation to be studied is selected, the representative of the site was carefully considered for the region in the study. Mineralogical and petrographic analyses of the stone material were investigated by using optical microscopy, X-ray diffraction (XRD), and scanning-electron microscopy (SEM).
The clay fraction in the stone samples was extracted using the following experimental procedure: $50 \mathrm{~g}$ of crushed limestone was soaked in a mixture of hydrogen peroxide $\left(\mathrm{H}_{2} \mathrm{O}_{2}\right)$ to remove any organic matter. Afterwards, $0.2 \mathrm{~N} \mathrm{HCl}$ was added to the residue, which was washed repeatedly with distilled water [12]. To separate the silt fraction, wet sieve analysis was used. The centrifugation was used to separate the clay fraction. Oriented clay aggregates (air-dried, ethylene glycol [EG]-, and heated $\left[550{ }^{\circ} \mathrm{C}\right]$ ) were prepared. XRD analysis of the oriented clay aggregates was performed with a Philips PW-1710 diffractometer. The pattern was run with $\mathrm{Cu}$ - radiation $(\lambda=1.542 \AA)$ at $40 \mathrm{KV}, 35 \mathrm{MA}$ and scanning speed $0.02 \%$ sec. were used. The scanning was limited from $2 \theta=2$ to $60^{\circ}$. The clay content was calculated from the weight of the clay fraction following drying at $70{ }^{\circ} \mathrm{C}$ for 24 hours.

\subsection{Physical and mechanical testing}

The hydric swelling was measured at room temperature on core samples ( $2 \mathrm{~cm}$ diameter and $4 \mathrm{~cm}$ length). Five samples were submerged in water except for $5 \mathrm{~mm}$ of the upper surface to prevent trapping gases and allow capillary water uptake. The vertical deformation was quantified with an AEP linear displacement transducer (LDT) with continuous data-logging connected to a computer, which, through the software MP4 Supervisor automatically records displacement values every $5 \mathrm{sec}$. for $24 \mathrm{hrs}$. The hydric expansion was obtained as the maximum value of the vertical deformation per initial length, $\Delta l / l 0$.

Water absorption by capillary is widely used for the characterization of building materials as it provides information about the pore structure and the accessibility of the pores. To assure that the samples reached the water saturation during the wetting cycle, the water absorption by capillary was measured according to the European standard EN-1925 [25]. The sample was dried at $50{ }^{\circ} \mathrm{C}$ until its weight became constant. Then it was placed in a water sheet of $3( \pm 1) \mathrm{mm}$ high. The weight increase was measured continuously. This increase in weight by surface unit was plotted as a function of time.

Twenty samples were subjected to 50 wetting/drying cycles. Samples were insulated around their circumference with sealing tape to prevent water evaporation from the sides. In each cycle, samples were submerged in distilled water at $20{ }^{\circ} \mathrm{C}$ for $10 \mathrm{hrs}$. Then, the samples were removed from the water and kept in an oven at $70{ }^{\circ} \mathrm{C}$ for 12 hrs. Finally, the samples were cooling during $2 \mathrm{hrs}$ at room temperature. After every 10 cycles 3 samples were removed for being subject to compressive strength testing. 
Stone strength was investigated by uniaxial compressive test. The uniaxial compressive strength can be measured by plotting applied force against deformation in a testing machine, determining the maximum value of stress attained before failure. In the test, 15 core samples were used, and the load rate of the machine was $0.53 \mathrm{MPa} / \mathrm{S}$.

\section{Results}

\subsection{Petrographic investigation}

Eocene limestone of Cairo and Giza is exposed in Mokkatam plateau and Helwan plateau at Eastern riverside of the Nile and Giza plateau at the western side of the Nile $[20,26,27]$. The test samples were taken from $15^{\text {th }}$ of May quarries at Helwan area. The results of petrographic study revealed the presence of three distinguishable microfacies types $[28,29]$ and that Helwan limestone is composed of very fine calcite micritic with scattered of foraminifera and minor amounts of quartz [26, 30]. The following parag-raphs are the main lithofacies listed in the present work:

\subsubsection{The bioclasts mudstone lithofacies}

The mudstone (Fig. 2) consists of micritic matrix in which skeletal allochems and rare quartz grains are embedded. The former is dominated by foraminiferal tests (miliolids, planktonic and Nummulites sp.) and echinoid fragments. Other skeletal grains include corals, ostracods, and unidentifiable bioclasts.

The lithoclasts are sand-sized, rounded and consist of micrite which may encompass fine quartz grains. Most of these lithoclasts are highly ferruginous, siliceous and, rarely, dolomitized. In a few cases, the micritic matrix is partially recrystallized into pseudospar which occurs as drusy calcite cement filling the moldic cavities (Fig. 2).

\subsubsection{Nummulites bioclasitc wackstone}

Skeletal allochems of this microfacies consist of foraminiferal tests and, much less commonly, echinoid fragments (Fig. 3). The forams are represented by (miliolids, planktonic, and biserial benthonic sp. Other skeletal grains are rare and include those of algal fragments, bryozoa, corals and ostracods. Quartz grains are rare and some display undulose extinction. Micro- to meso-crystalline drusy calcite cements are more abundant. Some lithoclasts show two stages of drusy calcite cementation. Syntaxial calcite overgrowths of neomalite fragments were recorded.

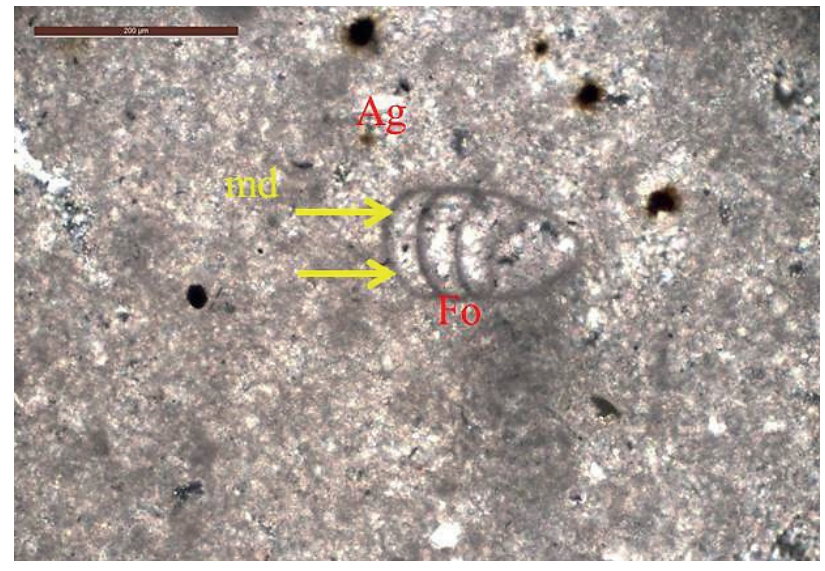

Fig. 2 Photo micro-image by polarizing microscope (PPL, 20x) describing the mudstone lithofacies (Md) of mokkatam limestone. The foraminifera (Fo) tests are partially recrystallized or aggrading neomorphism (Ag) into pseudospar which occurs as drusy calcite cement filling the moldic cavities, (see arrow)

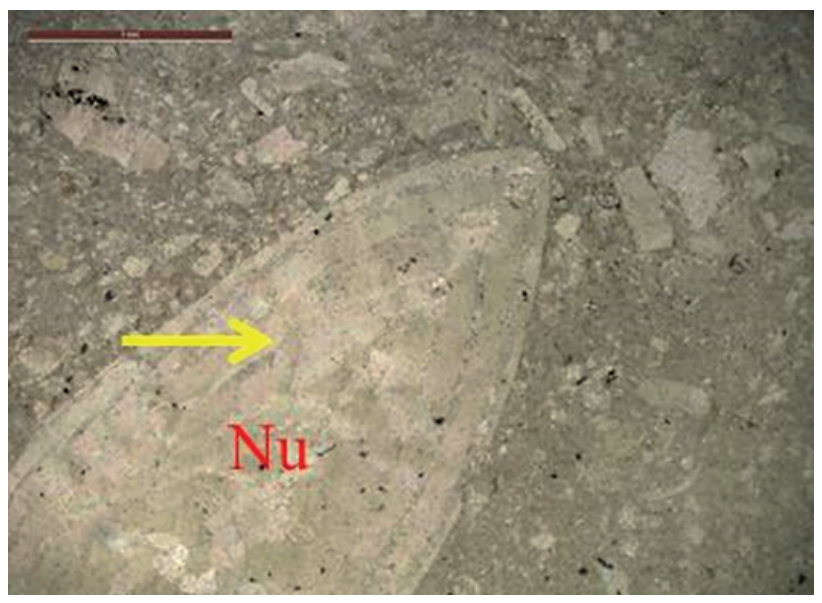

Fig. 3 Photo micro-image by polarizing microscope (PPL, 20x) describing nummulites bioclasitc wackstone. The Nummulites $(\mathrm{Nu})$ tests are completely recrystallized into pseudospar which occurs as drusy calcite cement filling the tests of Nummulites, (see yellow arrow)

\subsection{The experimental XRD patterns}

To identify the clay fraction component, XRD was the most efficient tool. The insoluble fraction of Helwan limestone was $12.3 \%$ by weight. The silt ( $2.3 \%$ by weight $)$ was separated by wet sieving analysis and clay $(10 \%$ by weight) fraction was separated by centrifugation. Oriented aggregates XRD analysis was performed for the clay fraction $<2 \mu \mathrm{m}$ and it confirmed the presence of swellable clay minerals by the peak at $15 \AA$ that expands to $17 \AA$ when glycolated and collapsed to $10 \AA$ after heating to $550{ }^{\circ} \mathrm{C}$ (Fig. 4). The clay minerals composing the clay fractions must be localized in the smectite grains fillings inside the tests of the bioclasts. 


\subsection{Scanning Electron Microscopy (SEM)}

Scanning Electron Microscopy (SEM) observations confirmed the XRD results with the presence of authigenic smectite (montmorillonite) filling the pore spaces of the stone material (Fig. 5(a, c)). In addition, abundance of glauconite pellets (an iron - rich mixed layer of illite/ smectite) between grains (Fig. 5(b, d)) can be observed.

\subsection{Geomechanical properties}

To simulate weathering tests, wetting-drying test was performed to analyze the effect of weathering on the compressive strength of rocks.

It was important to measure both the hydric expansion and the rate of capillary uptake before the performance of wetting - drying test to assign the wetting time enough for the tested sample to get saturated and to expect the damage behavior of the tested samples.

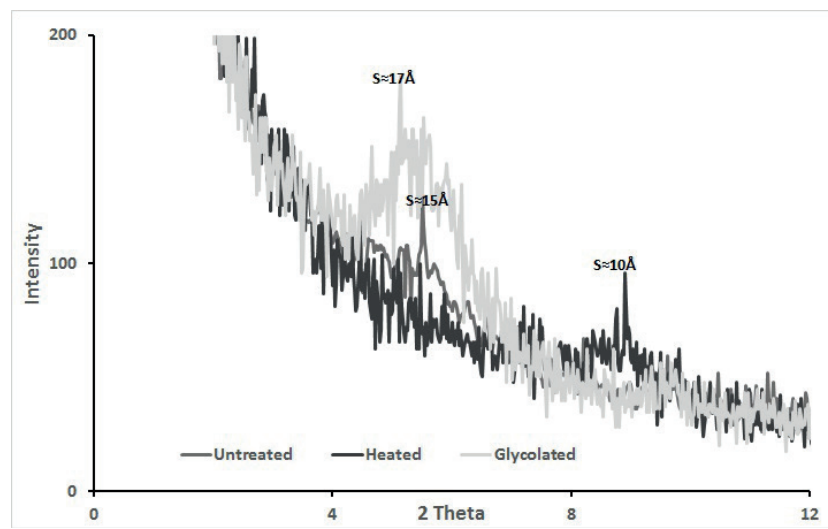

Fig. 4 XRD pattern of air-dried, EG solvated and after heating at $550{ }^{\circ} \mathrm{C}$ orientated aggregates Clay fraction
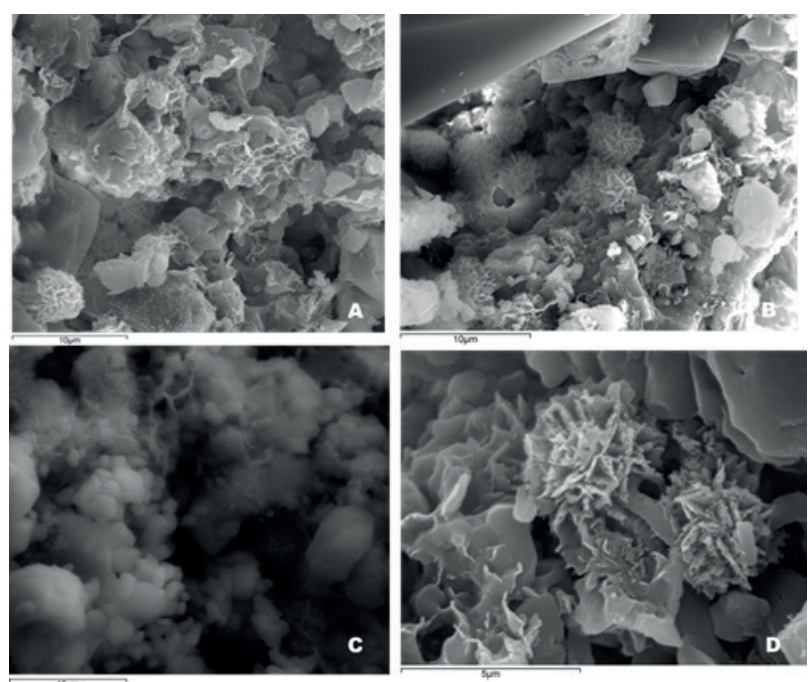

Fig. 5 (a) and (c) SEM micrographs of the studied limestone showing smectite (S) crystals filling the pores, (b) glauconitic spherules developed between calcite grains, and (d) close view showing the gluconite
Fig. 6 shows the hydric behavior through time of one of the tested cores. Although the stone material of tested samples is homogenous, the measured dilation coefficients varied in each sample and it ranged between 0.9 and $1.3 \mathrm{~mm} / \mathrm{m}$ which may be explained by the disproportionate distribution of clay within the tested samples.

The results of the capillary uptake showed that the sample reached to the full water saturation after nearly 8 hours, but the test was continued to 48 hours to ensure the stability of the readings (Fig. 7).

The initiation of microcracks on the upper surface of the tested samples was the first decay pattern developed after only 8 cycles during the drying cycle (Fig. 8(a)). The developed microcracks had the same direction, which might be the same orientation of the clay layers. After 20 cycles, some samples showed signs of breakdown and it was mostly during the drying cycle (Fig. 8(b)). At the end, most samples upper surface showed spalling, pitting and loss of material.

Decay was quantified by the percentage of weight loss $(\Delta \mathrm{W} \%)$ after each 5 cycles and by measuring the samples strength (UCS) after every 10 cycles. All the samples exhibit a loss of weight after different wetting /drying cycles. The obtained data represented in Table 1 showed a consistent weight loss after all the cycles, reaching up to $3.6 \%$ material loss after 50 cycles.

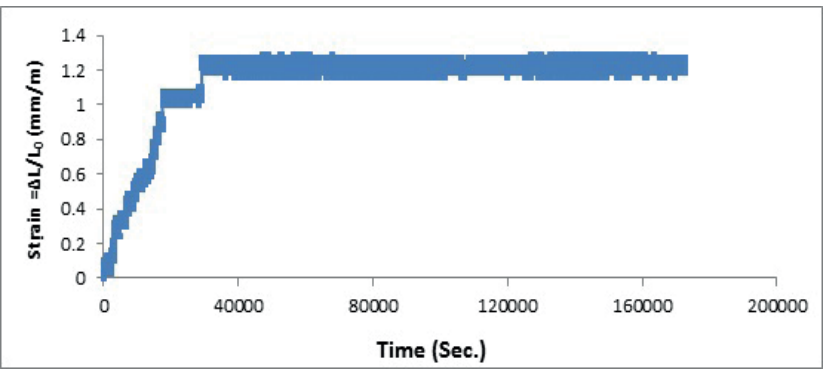

Fig. 6 Hydric dilation behavior versus time of a tested limestone core

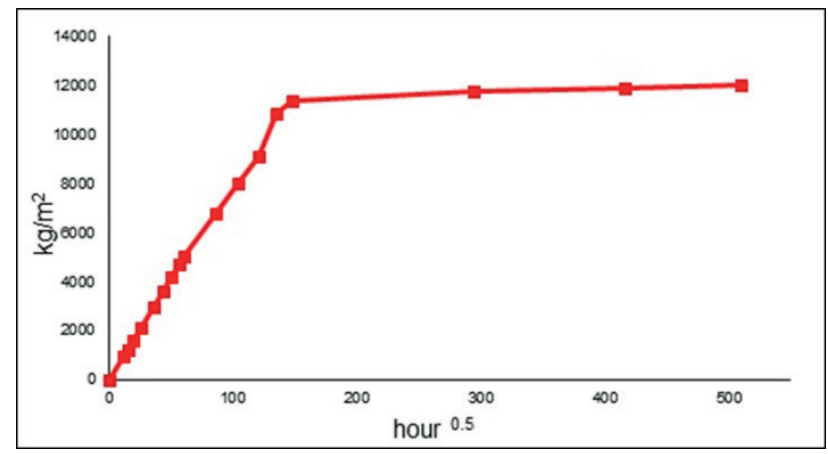

Fig. 7 Capillary uptake rate of the investigated limestone 

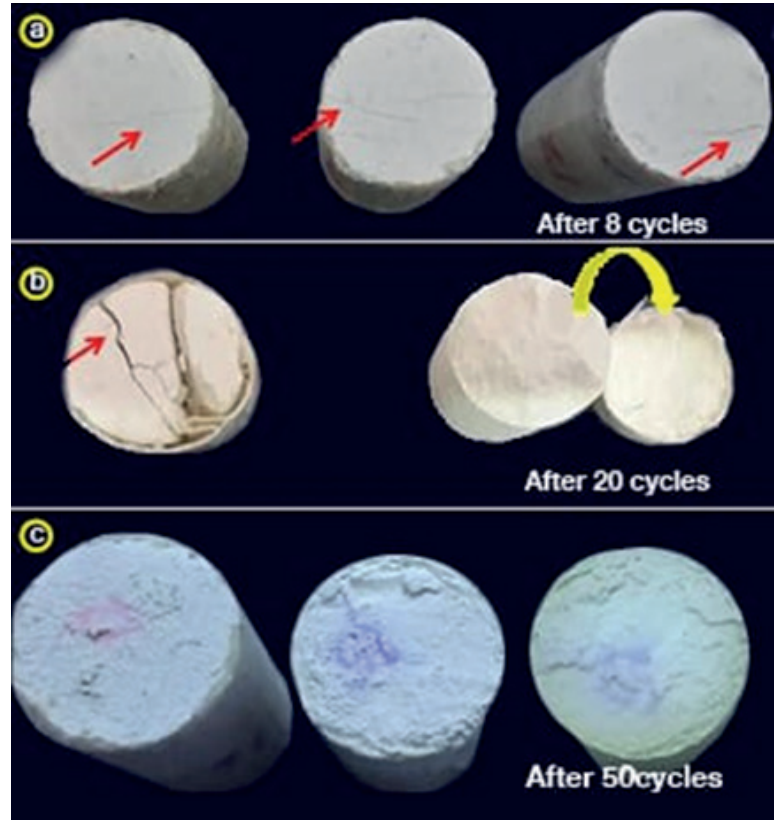

Fig. 8 Decay forming after the wetting/ drying cycles; (a) microcracks (see arrows); (b) breakage of samples; (c) material loss, surface spalling and small pits development

Table 1 weight loss of the tested samples after wetting /drying cycles

\begin{tabular}{lc}
\hline Cycle no. & Ave. $\Delta \mathrm{W} \%$ \\
\hline 5 & 1.1 \\
10 & 1.3 \\
15 & 1.8 \\
20 & 2.1 \\
25 & 2.4 \\
30 & 2.3 \\
35 & 1.8 \\
40 & 2.1 \\
45 & 2.8 \\
50 & 3.4 \\
\hline
\end{tabular}

Hydric expansion is considered an important factor for controlling the weathering behavior and deterioration of the building stones and typically associated with the presence of swellable clay minerals. The effect of hydric swelling on stone durability was assessed by measuring the uniaxial strength of the tested samples after every 10 drying/ wetting cycles (Fig. 9).

There is a trend towards a loss of strength in all samples after different cycles. The average value of UCS for quarry samples is $17.7 \pm 2.1 \mathrm{MPa}$, which decreased to $5.4 \mathrm{MPa}$ after 50 cycles.

Due to the expansive nature of smectite minerals, they act very active in environments with environmental fluctuations. The intracrystalline swelling of the clay layers could be interpreted as activation for the hydro-mechanical

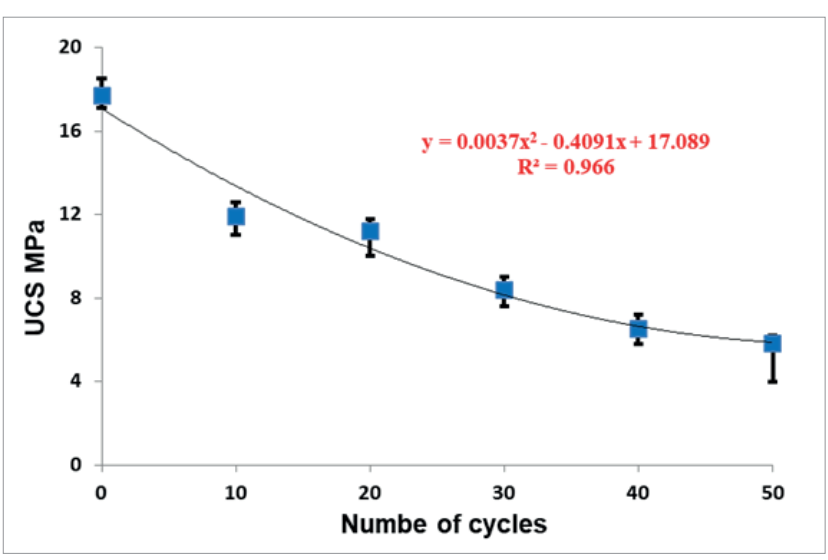

Fig. 9 Unconfined compression strength measurements for quarry

limestone cores and samples subjected to drying/wetting cycles

behavior. At the microscopic scale, the porous network when it filled by water molecules, it promotes the swelling of the clay interlayers resulting the displacement of the whole mineral structure. The porous network can be partially affording these displacements but sometimes the displacement moved to the solid matrix and result in hydric dilatation $[10,11,31]$. Few researchers attempted to measure the swelling pressure developed by hydric dilatation with experimental devices $[31,32]$. The effect of the swelling of clays and its resultant hydric dilation was so obvious in this study as it lowered the compressive strength of the investigated samples from $17.7 \pm 2.1 \mathrm{MPa}$, to $5.4 \mathrm{MPa}$ after only 50 cycles. This could be explained as the result of the stress relaxation of the stone when it gets wetted and the accompanied softening of its material [33]. To understand the different mechanisms of damage evolution, further studies on swelling pressure driven by hydraulic dilation need to be performed.

\section{Discussion and conclusions}

The petrographic investigation of the Helwan limestone revealed the presence of smectites and glauconites within the matrix of stone material. Based on the obtained results, swelling clay minerals (i.e. smectites) are considered as an important decay factor of building stones and leads to the crack development, spalling and breakdown of stone material.

When water enters the pore system of the limestone, clays start to expand extensively due to the innercrystalline swelling. When the generated tensile stresses that resist the contraction of the upper surface of the sample after drying cycles exceeded the tensile strength of stone material the surface layer starts to exhibit different damage patterns and the weight successively begins to be lost. 
The results of this study showed that the clay fraction within Helwan limestone (10\% by weight) produced a noticeable swelling strain that affects mightily on the mechanical behavior of the tested samples as it leads to a strength reduction close to $70 \%$ and $3.6 \%$ material loss after only 50 wetting/drying cycles. The swelling clay content should be taken into consideration during the study of deterioration phenomena of the built heritage in Historic Cairo in where Helwan limestone was used for constructing many monumental structures. In addition, this highlights

\section{References}

[1] Török, Á., Přikryl, R. "Current methods and future trends in testing, durability analyses and provenance studies of natural stones used in historical monuments", Engineering Geology, 115(3-4), pp. 139142, 2010. https://doi.org/10.1016/j.enggeo.2010.07.003

[2] Charola, A. E. "Salts in the Deterioration of Porous Materials: An Overview", Journal of the American Institute for Conservation, 39(3), pp. 327-343, 2000. https://doi.org/10.1179/019713600806113176

[3] Flatt, R. J., Aly, N., Caruso, F., Derluyn, H., Desarnaud, J., Lubelli, B., Espinosa-Marzal, R. M., Pel, L., Rodriguez-Navarro, C., Scherer, G. W., Shahidzadeh, N., Steiger, M. "Predicting salt damage in practice: a theoretical insight into laboratory tests", RILEM Technical Letters, 2, pp. 108-118, 2017. https://doi.org/10.21809/rilemtechlett.2017.41

[4] de la Calle, C., Suquet, H., Pons, C.-H. "Stacking Order in a 14.30- $\AA$ Mg-Vermiculite", Clays and Clay Minerals, 36(6), pp. 481-490, 1988.

https://doi.org/10.1346/CCMN.1988.0360601

[5] Jimenez Gonzalez, I., Scherer, G. W. "Effect of swelling inhibitors on the swelling and stress relaxation of clay bearing stones", Environmental Geology, 46, pp. 364-377, 2004.

https://doi.org/10.1007/s00254-004-1038-8

[6] Berthonneau, J., Grauby, O., Bromblet, P., Vallet, J.-M., Dessandier, D., Baronnet, A. "Role of swelling clay minerals in the spalling decay mechanism of the "Pierre du Midi" limestone (SouthEast of France)", presented at 12th International Congress on the Deterioration and Conservation of Stone, Columbia University, New York, NY, USA, Oct, 22-25, 2012.

https://doi.org/10.13140/RG.2.1.2415.3129

[7] Berthonneau, J., Grauby, O., Ferrage, E., Vallet, J.-M, Bromblet, P., Dessandier, D., Chaudanson, D., Baronnet, A. "Impact of swelling clays on the spalling decay of building limestones: insights from X-ray diffraction profile modeling", European Journal of Mineralogy, 26(5), pp. 643-656, 2014.

https://doi.org/10.1127/0935-1221/2014/0026-2393

[8] Berthonneau, J., Bromblet, P., Cherblanc, F., Ferrage, E., Vallet, J.-M, Grauby, O. "The spalling decay of building bioclastic limestones of Provence (South East of France): From clay minerals swelling to hydric dilation", Journal of Cultural Heritage, 17, pp. 53-60, 2016.

https://doi.org/10.1016/j.culher.2015.05.004 the importance of controlling the presence of swelling clay, when Helwan limestones are selected for new constructions or restoration of historical buildings of Giza.

\section{Acknowledgement}

The authors want to express their extreme gratitude to Dr. David Benavente, (Departamento de Ciencias de la Tierra y del Medio Ambient Universidad de Alicante, Spain) for his valuable recommendations and Dr. Timothy Wangler, $(\mathrm{ETH}$ Zurich, Switzerland) for his comments on the manuscript.

[9] Cherblanc, F., Berthonneau, J., Bromblet, P., Huon, V. "Influence of Water Content on the Mechanical Behaviour of Limestone: Role of the Clay Minerals Content", Rock Mechanics and Rock Engineering, 49, pp. 2033-2042, 2016. https://doi.org/10.1007/s00603-015-0911-y

[10] Tiennot, M., Mertz, J.-D., Bourgès, A. "Influence of Clay Minerals Nature on the Hydromechanical and Fracture Behaviour of Stones", Rock Mechanics and Rock Engineering, 52, pp. 1599-1611, 2019. https://doi.org/10.1007/s00603-018-1672-1

[11] Guy, N., Seyedi, D. M., Hild, F. "Characterizing Fracturing of Clay-Rich Lower Watrous Rock: From Laboratory Experiments to Nonlocal Damage-Based Simulations", Rock Mechanics and Rock Engineering, 51, pp. 1777-1787, 2018. https://doi.org/10.1007/s00603-018-1432-2

[12] Rodriguez-Navarro, C., Hansen, E., Sebastian, E., Ginell, W. S. "The Role of Clays in the Decay of Ancient Egyptian Limestone Sculptures", Journal of the American Institute for Conservation, 36(2), pp. 151-163,1997. https://doi.org/10.1179/019713697806373172

[13] Rodriguez-Navarro, C., Sebastian, E., Doehne, E., Ginell, W. S. "The role of sepiolite-palygorskite in the decay of ancient Egyptian limestone sculptures", Clays and Clay Minerals, 46(4), pp. 414422, 1998. https://doi.org/10.1346/CCMN.1998.0460405

[14] Madsen, F. T., Müller-Vonmoos, M. "The swelling bahaviour of clays", Applied Clay Science, 4(2), pp. 143-156, 1989. https://doi.org/10.1016/0169-1317(89)90005-7

[15] Benavente, D., Cultrone, G., Gómez-Heras, M. "The combined influence of mineralogical, hygric and thermal properties on the durability of porous building stones", European Journal of Mineralogy, 20(4), pp. 673-685, 2008. https:/doi.org/10.1127/0935-1221/2008/0020-1850

[16] Halsey, D. P., Mitchell, D. J., Dews, S. J. "Influence of climatically induced cycles in physical weathering", Quarterly Journal of Engineering Geology and Hydrogeology, 31(4), pp. 359-367, 1998. https://doi.org/10.1144/GSL.QJEG.1998.031.P4.09

[17] Weiss, T., Siegesmund, S., Kirchner, D., Sippel, J. "Insolation weathering and hygric dilatation: two competitive factors in stone degradation", Environmental Geology, 46(3-4), pp. 402-413, 2004. https://doi.org/10.1007/s00254-004-1041-0 
[18] Jimenez-González, I., Rodríguez-Navarro, C., Scherer, G. W. "Role of clay minerals in the physicomechanical deterioration of sandstone", Journal of Geophysical Research: Earth Surface, 113(F2), Article ID: F02021, 2008. https://doi.org/10.1029/2007JF000845

[19] Klemm, R., Klemm, D. D. "Stones and Quarries in Ancient Egypt", British Museum Press, London, UK, pp. 354-367. 2008.

[20] Fitzner, B., Heinrichs, K., La Bouchardiere, D. "Limestone weathering of historical monuments in Cairo, Egypt", In: Siegesmund, S., Weiss, T., Vollbrecht, A. (eds.) Natural Stone, Weathering Phenomena, Conservation Strategies and Case Studies, Geological Society, London, UK, 2002, pp. 217-239. https://doi.org/10.1144/GSL.SP.2002.205.01.17

[21] Harrell, J. A., Storemyr, P. "Ancient Egyptian quarries - an illustrated overview", Geological Survey of Norway Special Publication, 12, pp. 7-50, 2009. [online] Available at: https://www.ngu.no/upload/ Publikasjoner/Special\%20publication/SP12_s7-50.pdf [Accessed: 28 March 2020]

[22] Ahmed, H. T. "Physical and Mechanical Characteristics of Helwan Limestone: For Conservation Treatment of Ancient Egyptian Limestone Monuments", Journal of American Science, 11(2), pp. 136-151, 2015.

https://www.doi.org/10.7537/marsjas110215.18

[23] Awad, M., Abdel-Baki, A. "Water quality and environmental tritium for groundwater of the Quaternary aquifer in Mostorad station, northward Cairo, Egypt", Bulletin of the Faculty of Science, Assiut University, 22(2-F), pp. 173-191, 1993.

[24] Said, R. "The Geology of Egypt", Elsevier Science, Rotterdam, Netherlands, 1992.

[25] BSI "BS EN 1925:1999 Natural stone test methods, Determination of water absorption coefficient by capillarity", British Standards Institution, London, UK, 1999.
[26] Ahmed, H., Török, Á., Lőcsei, J. "Performance of some commercial consolidating agents on porous limestones from Egypt", In: Proceedings of the International Heritage, Weathering and Conservation Conference (HWC-2006), Madrid, Spain, 2006, pp. 735-740.

[27] Tawadros, E. E. "Geology of Egypt and Libya", Balkema, Rotterdam, Netherlands, 2001

[28] Folk, R. L. "Practical Petrographic Classification of Limestones", AAPG BUlletin., 43(1), pp. 1-38, 1959. https://doi.org/10.1306/0BDA5C36-16BD-11D7-8645000102C1865D

[29] Folk, R. L. "Spectral subdivision of limestone types", AAPG Bulletin, A038, pp. 62-84, 1962.

[30] Aly, N., Gomez-Heras, M., Hamed, A., Álvarez de Buergo, M. Soliman, F. "The influence of temperature in a capillary imbibition salt weathering simulation test on Mokkattam limestone", Materiales de Construcción, 65(317), Article ID: e044, 2015. https://doi.org/10.3989/mc.2015.00514

[31] Ruedrich, J., Bartelsen, T., Dohrmann, R., Siegesmund, S. "Moisture expansion as a deterioration factor for sandstone used in buildings", Environmental Earth Science, 63, pp. 1545-1564, 2011. https://doi.org/10.1007/s12665-010-0767-0

[32] Colas, E., Mertz, J. D., Thomachot-Schneider, C., Barbin, V., Rassineux, F. "Influence of the clay coating properties on the dilation behavior of sandstones", Applied Clay Science, 52(3), pp. 245252,2011 https://doi.org/10.1016/j.clay.2011.02.026

[33] Aly, N., Wangler, T., Török, Á. "The effect of stylolites on the deterioration of limestone: possible mechanisms of damage evolution", Environmental Earth Sciences, 77, Article Number: 565, 2018. https://doi.org/10.1007/s12665-018-7746-2 